\title{
Marketing digital, E-commerce e pandemia: uma revisão bibliográfica sobre o
}

\section{panorama brasileiro}

\author{
Digital marketing, E-commerce and pandemia: a bibliographic review on the brazilian panorama \\ Marketing digital, comercio electrónico y pandemia: una revisión bibliográfica del panorama \\ brasileño
}

Recebido: 14/04/2021 | Revisado: 20/04/2021 | Aceito: 28/04/2021 | Publicado: 13/05/2021

\author{
Walyson Monteiro da Silva \\ ORCID: https://orcid.org/0000-0002-4650-2802 \\ Universidade Estadual da Paraíba, Brasil \\ E-mail: walyson_zo@hotmail.com \\ Lucas Andrade de Morais \\ ORCID: https://orcid.org/0000-0003-4443-2393 \\ Universidade Estadual da Paraíba, Brasil \\ Universidade do Estado do Rio Grande do Norte, Brasil \\ E-mail: lucasmorais7@gmail.com \\ Cinthia Moura Frade \\ ORCID: https://orcid.org/0000-0002-2826-816X \\ Universidade Estadual da Paraíba, Brasil \\ Instituto Federal da Paraíba, Brasil \\ E-mail: admcinthiafrade@gmail.com \\ Mariana Ferreira Pessoa \\ ORCID: https://orcid.org/0000-0002-1563-5469 \\ Universidade do Estado do Rio Grande do Norte, Brasil \\ E-mail: marianafepessoa@gmail.com
}

\begin{abstract}
Resumo
No final do ano de 2019 passaram a eclodir as primeiras notícias de que um vírus, mapeado primeiramente na China, estaria se espalhando de maneira bastante veloz e com alto potencial de letalidade entre os infectados. O Sars-cov-2, popularmente conhecido como novo coronavírus, gerou a pandemia do Covid-19 que trouxe profundas transformações nas sociedades, nas relações interpessoais e no mercado empresarial em todo o mundo, causando fortes impactos nos setores produtivos e na economia, bem como na forma das empresas se posicionarem no mercado, tendo que se adaptarem às novas exigências e necessidades dos consumidores. Nessa perspectiva, uma das estratégias introduzidas ou aperfeiçoadas nas vendas ocorreram no âmbito digital, o que norteou a realização do presente estudo, que teve como objetivo realizar uma revisão bibliográfica para analisar os impactos gerados pela pandemia da Covid19 no posicionamento estratégico de marketing digital e e-commerce das empresas no país. Para subsidiar o estudo, foi adotado o enfoque qualitativo, por meio da utilização da pesquisa bibliográfica. Conclui-se que a pandemia acelerou o futuro de implementação maciça do comércio digital, gerando um crescimento acima da média de novos usuários do e-commerce no Brasil, além de impor aos empresários a necessidade de se reinventarem, elaborarem estratégias de marketing digital e adaptarem seus negócios ao novo contexto de consumo. A estratégia vem se mantendo vantajosa, existindo grande tendência de que sejam mantidas estas técnicas de vendas no período póspandemia.
\end{abstract}

Palavras-chave: Marketing digital; E-commerce; Pandemia.

\begin{abstract}
At the end of 2019, the first news broke that a virus, first mapped in China, was spreading very quickly and with a high potential for lethality among those infected. Sars-cov-2, popularly known as the new coronavirus, generated the Covid-19 pandemic that brought about profound transformations in societies, interpersonal relationships and the business market worldwide, causing strong impacts on the productive sectors and the economy, as well as the way companies position themselves in the market, having to adapt to the new demands and needs of consumers. In this perspective, one of the strategies introducedor improved sales occurred in the digital sphere, which guided the realization of the present study, which aimed to carry out a bibliographic review to analyze the impacts generated by the Covid-19 pandemic in the strategic positioning of digital marketing and e-commerce of companies in the parents. To support the study, a qualitative approach was adopted, through the use of bibliographic research. It is concluded that the pandemic accelerated the future of massive implementation of digital commerce, generating a growth above the average of new users of e-commerce in Brazil, in addition to imposingentrepreneurs need to reinvent themselves, develop digital marketing strategies and adapt their businesses to the new context of
\end{abstract}


consumption. The strategy has remained advantageous, with a strong tendency for these sales techniques to be maintained in the post-pandemic period.

Keywords: Digital marketing; E-commerce; Pandemic.

\section{Resumen}

A finales de 2019, se conoció la primera noticia de que un virus, mapeado por primera vez en China, se estaba propagando muy rápidamente y con un alto potencial de letalidad entre los infectados. El sars-cov-2, conocido popularmente como el nuevo coronavirus, generó la pandemia Covid-19 que provocó profundas transformaciones en las sociedades, las relaciones interpersonales y el mercado empresarial a nivel mundial, provocando fuertes impactos en los sectores productivos y la economía, así como en la economía. forma en que las empresas se posicionan en el mercado, debiendo adaptarse a las nuevas demandas y necesidades de los consumidores. En esta perspectiva, una de las estrategias introducidaso mejoras en las ventas ocurridas en el ámbito digital, lo que orientó la realización de este estudio, que tuvo como objetivo realizar una revisión bibliográfica para analizar los impactos generados por la pandemia Covid-19 en el posicionamiento estratégico del marketing digital y comercio electrónico de las empresas en los padres. Para apoyar el estudio se adoptó un enfoque cualitativo, mediante el uso de la investigación bibliográfica. Se concluye que la pandemia aceleró el futuro de la implementación masiva del comercio digital, generando un crecimiento superior al promedio de nuevos usuarios de comercio electrónico en Brasil, además de imponerLos emprendedores necesitan reinventarse, desarrollar estrategias de marketing digital y adaptar sus negocios al nuevo contexto de consumo. La estrategia ha seguido siendo ventajosa, con una fuerte tendencia a que estas técnicas de venta se mantengan en el período pospandémico.

Palabras clave: Marketing digital; Comercio electrónico; Pandemia.

\section{Introdução}

O Brasil, assim como os demais países do mundo, vem vivenciando desde 2020 uma situação atípica decorrente da Covid-19, doença provocada pelo novo coronavírus, segundo a Organização Mundial de Saúde, o que impôs diversas mudanças nos hábitos das sociedades. A pandemia trouxe consigo a necessidade de tomadas de decisões e adoções urgentes de estratégias para preservar vidas e conter a propagação da pandemia (Fiocruz, 2020).

Cientistas, estudiosos e autoridades do mundo inteiro passaram a recomendar o isolamento e distanciamento social como a maneira mais eficaz para conter o avanço do vírus. Esse novo contexto imposto pela crise sanitária gerou, por óbvio, reflexos no mercado de consumo bem como na atuação das empresas, que precisaram se reinventar e inovar, a fim de atender às novas demandas de atendimento aos consumidores e não serem sucumbidas pela crise (Almeida, Froemming e Ceretta, 2020).

Frente ao exposto, os hábitos de consumo passaram a ser à distância e, em vista disso, as empresas e prestadores de serviços necessitaram adotar estratégias para se adaptarem à nova realidade do atendimento remoto, que antes era apenas uma opção e atualmente passou a ser bastante utilizado tanto para compras, como para fornecimento de serviços. Nesse sentido, verifica-se que a pandemia tem funcionado como um acelerador de "futuros", pois a crise sanitária antecipou estratégias no mercado e na sociedade, a exemplo do trabalho remoto, da educação à distância, da necessidade de privilégio da sustentabilidade e da adoção de estratégias de marketing digital para fomentar o e-commerce.

É notório que houve várias transformações no cenário político, econômico, cultural, nos modelões de negócios, produção e consumo, nos relacionamentos interpessoais, na vivência dos cidadãos nos espaços públicos e com o meio ambiente, etc. Ademais, a pandemia gerou uma desaceleração da economia e das atividades empresariais, que tiveram que reduzir os trabalhos ou mesmo cessá-los diante das restrições sanitárias impostas, o que desencadeou mudanças essenciais no comportamento dos consumidores, bem como na forma de posicionamento das empresas no mercado.

Durante o isolamento social, novos hábitos e formas de consumo foram criados e adaptados a essa nova realidade, e o e-commerce passou a ser uma ferramenta essencial para as empresas se manterem ativas e fazerem com que seus produtos chegassem ao consumidor final, conforme atestou a pesquisa da Ebit-Nielsen (2020), a qual registrou um crescimento maior do que a média em relação aos novos consumidores do e-commerce brasileiro. Em termos percentuais, a referida pesquisa evidenciou, no período referente ao primeiro semestre de 2020 , um crescimento de $47 \%$ no faturamento das lojas online. 
Especificamente no decorrer do mês de abril de 2020, contexto inicial da pandemia no Brasil, o comércio eletrônico demonstrou um crescimento de $81 \%$ quando comparado ao mês de abril do ano anterior.

Nessa nova conjuntura, as estratégias de promoção e vendas pelo comércio foram reinventadas pelas empresas, pois as vendas que antes eram majoritariamente físicas migraram para o ambiente virtual, demandando a adoção de novas estratégias de marketing por parte das organizações, com a utilização em grande escala de sites e redes sociais para divulgação dos produtos e serviços (Rezende, Marcelino \& Miyaji, 2020).

A internet, nesse sentido, tem sido uma ferramenta bastante utilizada por empresas e pelos consumidores para venda e aquisição de produtos e serviços, e nesse novo cenário imposto pela pandemia, o e-commerce passou a ser utilizado em larga escala em todo o mundo, possibilitando a manutenção de operações comerciais e financeiras e o atendimento das novas exigências dos consumidores de atuação sustentável por parte das empresas.

O comércio eletrônico, desse modo, passou a se apresentar como protagonista na relação entre empresas e consumidores, os quais se tornaram mais exigentes nas compras, pois estas podem ser feitas a qualquer lugar por meio do uso da internet, evitando-se filas e havendo a facilidade de uma vasta pesquisa para comparação de preços e qualidade dos produtos ofertados, o que impôs às empresas a necessidade de se reinventarem para angariar e fidelizar sua clientela, bem como se habituarem às novas transações comerciais.

Diante dessa nova realidade, o presente estudo parte do seguinte questionamento: Qual(is) efeito(s) da pandemia do novo coronavírus nas estratégias de vendas online e marketing digital em empresas do mercado brasileiro na perspectiva da produção científica? Para tanto, tem-se como objetivo geral realizar uma revisão bibliográfica para analisar os impactos gerados pela pandemia da Covid-19 no posicionamento estratégico de marketing digital e vendas das empresas, discorrendo sobre as transformações ocorridas no âmbito da prestação dos serviços e atendimento ao consumidor diante da nova realidade vivenciada pelo mundo.

Como objetivos específicos, o estudo busca discorrer, com base na revisão bibliográfica realizada, acerca da pandemia do coronavírus sob a ótica da necessidade de sustentabilidade empresarial; abordar o e-commerce e o comportamento do consumidor no "novo normal"; e analisar o fomento do $e$-commerce no cenário atual e a demanda pelo marketing inteligente.

\section{Metodologia}

Trata-se de um estudo de natureza qualitativa, pois essa escolha metodológica permite explorar e compreender um problema no contexto social (Creswell, 2010). Com isso, foi possível o entendimento das informações referentes ao novo cenário vivenciado no mundo a partir da pandemia do Covid-19, sendo analisados os impactos dessa crise sanitária no cenário social e empresarial brasileiro.

Para tanto, o estudo se norteou pela revisão bibliográfica como técnica de pesquisa, por meio da qual foram analisadas publicações acadêmicas sobre os impactos da pandemia no contexto das organizações, bem como a importância do marketing digital e do e-commerce como vantagem competitiva no mercado e para fidelização de consumidores. Foram pesquisados artigos na plataforma "Google acadêmico", sendo selecionadas publicações compreendidas no intervalo de abril a outubro de 2020, além de serem utilizados literaturas, relatórios e notícias que tratam da temática do marketing digital e do e-commerce.

Após esse processo, os dados coletados foram submetidos a análise interpretativa, a partir de uma posição própria no que diz respeito as ideias analisadas, assim, a exploração das mesmas, do ponto de vista estrutural, permitiu o desenvolvimento do entendimento interpretativo acerca do assunto estudado, bem como, o estabelecimento de "[...] uma aproximação e um associação das ideias expostas no texto com ideias semelhantes que eventualmente tenham recebido outra abordagem [...], o que norteou a fundamentação crítica a partir das leituras realizadas (Severino, 2007, p. 60). 


\section{Resultados e Discussão}

\subsection{A pandemia do coronavírus e a necessidade de sustentabilidade empresarial}

No final do ano de 2019, passou a ser notícia no mundo sobre um novo tipo de vírus que causava graves infecções respiratórias e tinha alto potencial de transmissão foi descoberto na China. Trata-se de uma nova cepa do coronavírus (2019nCoV) que foi notificada em humanos pela primeira vez na cidade de Wuhan, na província de Hubei, na China (Fiocruz, 2020). Desde então, o vírus passou a se espalhar rapidamente na China, avançando pelo mundo e atingindo o Brasil no início do ano de 2020 .

Oficialmente, o primeiro caso da Covid-19 no Brasil foi registrado em 26 de fevereiro, contudo, investigações retrospectivas das ocorrências da síndrome respiratória aguda grave (SRAG) permitiram identificar casos positivos ainda em janeiro (Lemos, 2020). A Organização das Nações Unidas (ONU) avalia que a pandemia do novo coronavírus trata-se do maior desafio vivenciado pela humanidade desde a Segunda Guerra Mundial. Tudo tem se transformado, à medida em que velhos hábitos deixam de fazer sentido, enquanto novos modelos, recursos e comportamentos emergem para conduzir a sociedade (PiccolottO, 2020).

A rápida transmissão do vírus colocou em alerta a comunidade médica, cientistas, autoridades e a sociedade como um todo, que precisaram adotar rápidas estratégias de prevenção e tratamento da nova doença. Como se trata de uma enfermidade ainda pouco conhecida, o isolamento social e o distanciamento entre os indivíduos passou a ser a estratégia mais eficaz para conter os avanços da epidemia. Em virtude disso, o lockdown, estratégia de fechamento total de cidades, com proibição dos indivíduos de sair de casa e de abertura de estabelecimentos comerciais, passou a ser a determinação na maioria dos países do mundo. Nesse cenário, as empresas e prestadores de serviços precisaram se adaptar à nova demanda do mercado, na qual os consumidores passaram a adquirir produtos e contratar serviços em casa, de forma remota.

Além disso, a indicação de que o novo coronavírus tenha passado de um ambiente selvagem para o urbano, apontando um grave desequilíbrio ecológico, gerou uma discussão que aponta para a urgente necessidade de um controle dos níveis de consumo e produção e, obviamente, o uso consciente dos recursos naturais (Maciel, 2020). A crise sanitária desencadeada pelo novo coronavírus, então, passou a ocasionar um impacto sem precedentes no mercado empresarial de todo o mundo, pois, com o início da pandemia apenas os serviços essenciais, como supermercados e farmácias, puderam continuar a vender seus produtos em lojas físicas, ficando os demais serviços proibidos de fazê-lo.

Diante da impossibilidade de combater os efeitos nocivos da pandemia por meio da medicina, a dificuldade das pequenas e grandes potências mundiais em conter o avanço do vírus e o lockdown de cidades, os setores produtivos considerados não essenciais, que geravam aglomeração, tiveram suas atividades físicas paralisadas, causando rupturas na promoção e oferta de bens e serviços e, assim, alterando a maneira do consumidor de acessar tais produtos e serviços. Portanto, nessa nova realidade vivenciada em virtude das políticas de contenção do vírus, todos os agentes sociais e econômicos, como indivíduos, empresas e governos, tiveram que modificar seu comportamento de consumo (Rezende et al., 2020).

Em decorrência dos efeitos da pandemia do coronavírus, ainda impactando toda a economia global, o mercado empresarial teve que se reinventar, sendo possível afirmar, hoje, que é bastante difícil o retorno do varejo ao modelo de "normalidade" que imperava antes da pandemia, visto que as mudanças no comportamento do consumidor de certo poderão ser duradouras. Isso porque, além dos muitos varejistas tradicionais que observam o tráfego de pedestres e as vendas caírem para quase zero, a mudança mais profunda no comportamento do consumidor está ocorrendo no comércio eletrônico - e essa provavelmente terá uma das consequências mais duradouras, além da maior exigência por parte dos consumidores para que as empresas prezem pela sustentabilidade e adotem estratégias para reduzir os impactos causados pela crise sanitária, já com vistas a evitar que futuramente outra pandemia possa vir a ocorrer.

A sustentabilidade adotada pelas empresas, nessa perspectiva, passou a ser um aspecto ainda mais decisivo para os 
consumidores escolherem determinado tipo de produto ou serviço, tornando-se, assim, um fator de maior competitividade entre as organizações. Trata-se, portanto, de um conceito que gera marketing positivo para as organizações nesse novo cenário que o mundo vivencia. Melo (2017) enfatiza que a sustentabilidade empresarial é um conceito que aborda a capacidade de a empresa ser sustentável economicamente, socialmente e ambientalmente, prezando, sempre, pelo consumo consciente das matériasprimas utilizadas para a fabricação dos produtos ofertados pela empresa.

Construída sob o tripé responsabilidade social, responsabilidade ambiental e econômica, a sustentabilidade ganhou, a partir da pandemia da Covid-19, um novo significado. Neste contexto mundial em que as expectativas da sociedade com relação às empresas são crescentes, a incorporação dos aspectos sociais e ambientais às estratégias e práticas de governança corporativa ganham cada vez mais importância e oferecem vantagens competitivas às organizações (Gouvêa, 2020).

Portanto, há uma exigência de novas posturas de atuação por partes das empresas no que se refere à sustentabilidade, pensando numa perspectiva mais colaborativa, com propósitos de geração de valor para a sociedade, pois são fatores importantes para o aumento do número de vendas e credibilidade da marca durante e após o contexto de pandemia (Batista, Saran, Limongi, Silva \& Gomes, 2020), o que poderá ajudar tais organizações a sobreviverem.

A organização que se adaptar a essa nova realidade, de certo, terá vantagem competitiva no mercado. Pode-se perceber que questões sanitárias e econômicas possuem um impacto direto nas vidas de todos os seres humanos, refletindo, também, nos hábitos de consumo à medida em que a população altera suas prioridades e recorre a meios alternativos para satisfazer suas necessidades.

Portanto, neste cenário em que há a escassez de produtos e a impossibilidade de acesso a lojas físicas, as empresas tiveram que direcionar suas vendas para o meio digital, que antes era tido como ferramenta acessória e agora passou a ser um instrumento essencial para manutenção das atividades diante dos novos hábitos de consumo no contexto do "novo normal".

\subsection{O e-commerce e o comportamento do consumidor no contexto de pandemia da Covid-19}

Historicamente, desde que o comércio de mercadorias passou a ser realizado no ambiente virtual, grande parte de consumidores evitava esse tipo de compra, visto que a maioria destes preferiam visitar as lojas para adquirir seus itens sob a justificativa de se sentirem mais confiantes para aquisição dos produtos por poderem vê-los em suas reais dimensões e funcionamento, além do medo de golpes em sites e endereços eletrônicos falsificados (Lara et al., 2020).

Tal realidade há pouco tempo, também, se aplicava à aquisição de mantimentos de maneira online, por exemplo, mais da metade dos usuários de internet na Alemanha que possuíam idade entre 18 e 69 anos, disseram que nunca comprariam mantimentos pela internet, segundo pesquisa realizada em setembro de 2019 pela Ibi research e pela Digital Commerce Research Network (Guimarães Júnior et al., 2020).

Contudo, o comércio eletrônico, nesse contexto social imposto pela crise do coronavírus, vem tendo um momento de forte consolidação, no qual milhões de compradores estão realizando compras online pela primeira vez e, outros, que pouco tinham esse costume de aquisição de produtos por meio da internet estão fazendo-o cada vez mais. Conforme apontou a pesquisa da Ebit-Nielsen (2020), a necessidade, somada ao aumento na confiança em relação aos pagamentos realizados de forma online, fizeram com que 7,3 milhões de brasileiros realizassem uma compra pela primeira vez no $e$-commerce.

Porém, a crise do coronavírus afetou fortemente a economia global, despencando bolsas de valores, falindo empresas e colocando diversos setores do mercado em uma situação financeira crítica. A crise teve tamanha proporção que causou transformações na maneira como as pessoas consomem, pois, o comércio físico foi interditado temporariamente, fazendo com que o e-commerce passasse a crescer de maneira acelerada.

A comunidade científica, após mobilização incessante, desenvolveu vacinas eficazes contra o novo coronavírus e estima-se que, após a imunização da sociedade, a qual ainda está vivenciando este processo, os consumidores possam retornar 
maciçamente às lojas físicas tal como faziam no período anterior à pandemia. No entanto, em virtude dos novos hábitos de consumo e da nova realidade imposta às empresas pela crise sanitária, as estratégias de vendas virtuais e o marketing digital são ferramentas que vieram para ficar permanentemente no contexto das organizações (Almeida et al., 2020), estratégias estas que já eram utilizadas, mas, nesse novo contexto, foram aprimoradas e melhor exploradas.

No mercado de compra e venda, os hábitos das pessoas foram alterados, impulsionando um novo comportamento diante do trabalho, da vida pessoal e das compras de maneira remota. Um cômodo da casa foi transformado em um escritório, um smartphone se tornou ainda mais uma extensão dos braços e as telas são as ferramentas utilizadas para as interações entre as pessoas durante o isolamento social (Lara et al., 2020).

Com a alteração na dinâmica da vida, a rotina das pessoas foi flexibilizada com o trabalho remoto, o que também transformou os horários para realização de compras, pois os acessos virtuais cresceram e o consumidor passou a experimentar novos meios de realizar compras e pagar por elas, mostrando mais confiança nas transações virtuais (Guimarães Júnior et al., 2020). Além disso, se antes a maioria dos produtos e serviços adquiridos de maneira online eram em grande parte aqueles não essenciais, nos dias de hoje, praticamente todos os produtos são ofertados no ambiente online, inclusive aqueles de subsistência das pessoas.

Nesse contexto, as variáveis primordiais que determinam o consumo (como preço, propaganda, expectativas e renda do consumidor, tradição e hábitos culturais) ainda perduram, o que muda é o perfil de bens demandados. As pessoas passaram a buscar bens que lhes proporcionam uma situação de segurança diante da pandemia. No caso, principalmente produtos de higiene e limpeza, alimentos ou quaisquer outros que lhes permitam ter a sensação de segurança e proteção à vida (Rezende et al., 2020).

Essa foi uma realidade observada em todo o mundo a partir da crise sanitária desencadeada pelo novo coronavírus, mas a tendência de inserção da Internet e da tecnologia em geral em nossas vidas não vem de hoje. Por exemplo, durante o período de 2011 a 2018, as vendas através do e-commerce no Brasil saíram de 18,7 para 53,2 bilhões e essa evolução representou um CAGR (Compound Annual Growth Rate) de 16,1\% (Padua, 2020).

No Brasil, assim como na maioria dos países do mundo, o e-commerce vem se fortalecendo, o que pode ser evidenciado pelos dados da $42^{\mathrm{a}}$ edição do Webshoppers, por meio de um relatório semestral sobre o e-commerce do país, elaborado pela Ebit-Nielsen em parceria com a Elo, onde foi possível verificar que no primeiro semestre de 2020 o faturamento das lojas online cresceu 47\%, o maior em 20 anos. O Gráfico 1 mostra que no primeiro semestre do ano de 2019, o número de vendas era de $\mathrm{R} \$ 26,4$ bilhões contra $\mathrm{R} \$ 38,8$ bilhões no mesmo período do ano 2020:

Gráfico 1. Evolução do faturamento do e-commerce.

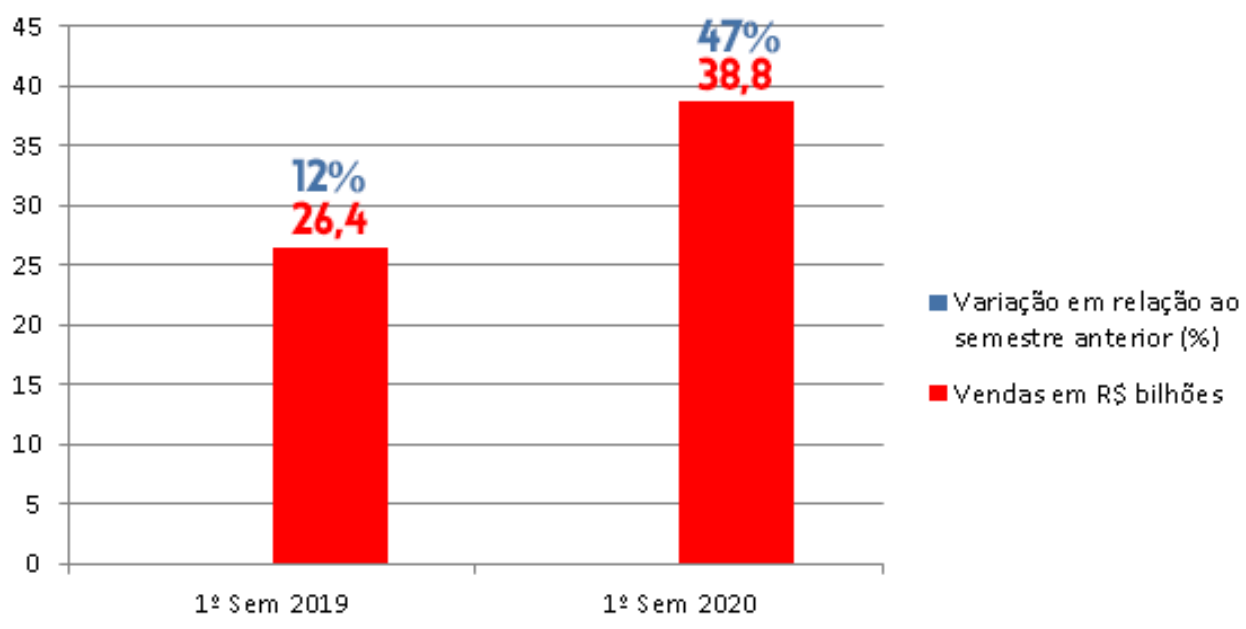

Fonte: Satatic poder 360, (2020). Adaptado pelo autor. 
Ao longo do mês de abril de 2020, o comércio eletrônico apresentou uma evolução de $81 \%$ em relação ao mês de abril de 2019. De acordo com a ABComm (Associação Brasileira de comércio eletrônico), alguns produtos que apresentaram um grande aumento no volume de vendas foram brinquedos/jogos $(+434,70 \%)$, supermercados $(+270,16 \%)$ e artigos esportivos (+211,95\%), conforme ilustra o Gráfico 2:

Gráfico 2. Aumento no volume das vendas.

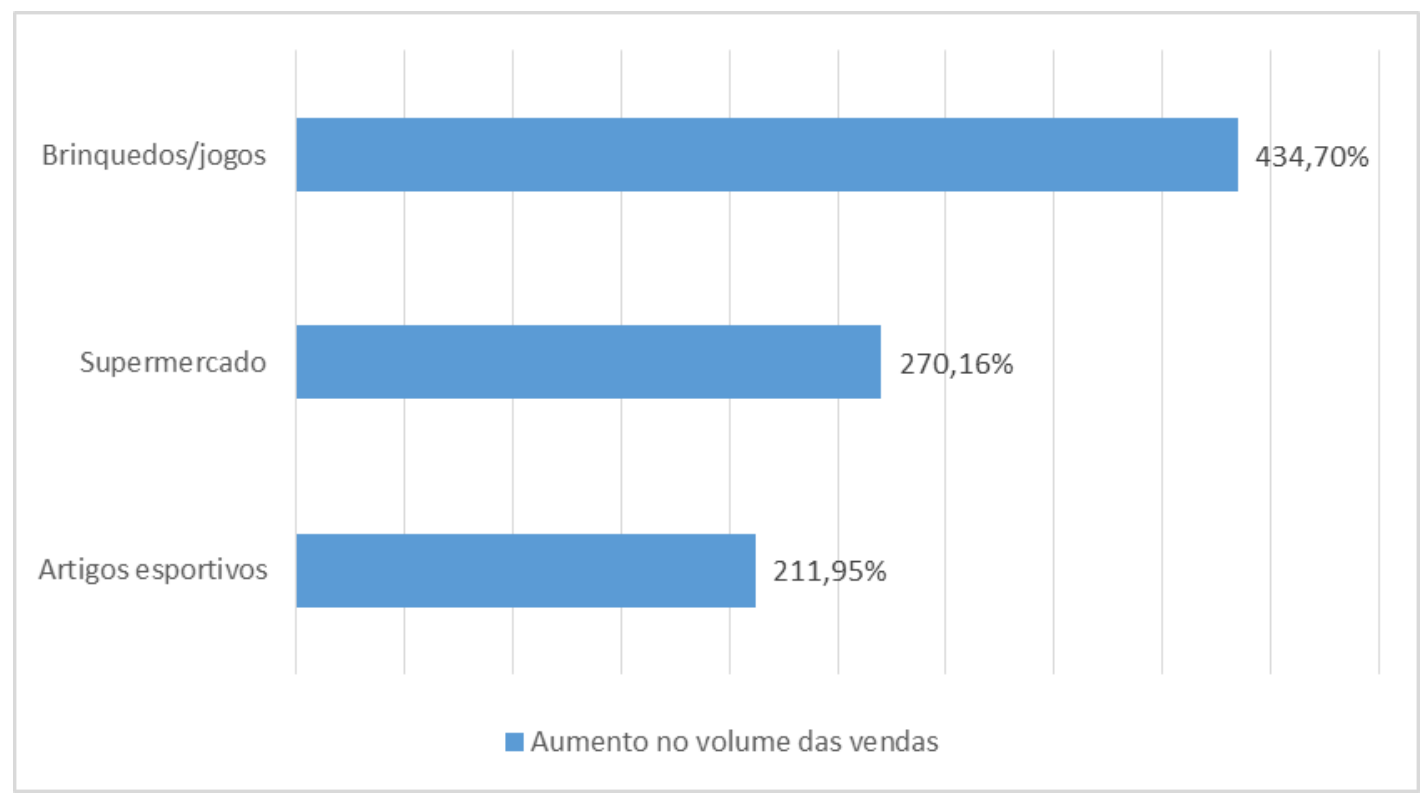

Fonte: ABComm (2020).

As razões que justificam esses aumentos foram, respectivamente, a necessidade de praticar exercícios sem sair de casa, necessidade de distração para crianças e de realização de compras evitando ao máximo sair de casa (Padua, 2020). Mesmo durante o primeiro trimestre de 2020, que foi menos afetado pelo fechamento de lojas no Brasil, a pandemia estimulou o e-commerce. As grandes varejistas de comércio eletrônico brasileiro, como Magazine Luiza, B2W e Via Varejo, apresentaram no 1T20 um aumento nas vendas online de, respectivamente, 72,6\%; 35\% e 52\% (Almeida et al., 2020).

Constata-se, diante disso, que a necessidade de ficar em casa, seja trabalhando ou não, com o objetivo de diminuir a disseminação do vírus, vem ocasionando mudanças profundas no comportamento das pessoas. Pode-se destacar, nesse sentido, que vem havendo um aumento no número de assinaturas de canais de TV ou plataformas de streaming, como a Disney+, HBO Now e Netflix. Um estudo elaborado pela Conviva, plataforma de monitoramento de streaming, aponta que a audiência desses serviços cresceu $20 \%$ no Brasil desde o início da pandemia de coronavírus (Rocha, 2020).

Em decorrência dos hábitos de consumo remotos, o mercado do marketing digital também vem tendo uma demanda aumentada, gerando uma crescente demanda por serviços de consultorias e agências de comunicação. Apesar de muitas enxergarem com dúvidas o futuro das ações de marketing, algumas empresas estão enxergando o surgimento de oportunidades, observando as novas tendências do mercado digital (Cruvinel, 2020).

De acordo com a Ebit-Nielsen (2020), considerando os seis primeiros meses de 2020, R\$ 30 bilhões do faturamento obtido vieram de lojas que desenvolveram marketplaces, o que representa um crescimento de 56\% comparado ao mesmo período do ano de 2019. Os marketplaces, como Amazon e Magazine Luiza, aumentaram consideravelmente o tráfego de consumidores em suas plataformas. Os produtos de higiene pessoal foram os que mais tiveram aumento nas vendas nessa pandemia, principalmente aqueles relacionados ao combate ao vírus, como o álcool gel. Outro setor que ficou aquecido com a crise e com a restrição das pessoas de irem a lugares públicos ou mesmo viajar foi o de alimentação. Isso fez com que bares e 
restaurantes que ainda não investiam em delivery tivessem que se adaptar rapidamente (Rocha, 2020).

Até mesmo as pequenas e médias empresas, que antes possuíam pouca ou nenhuma estratégia de marketing digital, passaram a buscar maneiras de implantar suas lojas virtuais e sistemas de entrega em casa. Esse processo de transformação configura-se como uma maneira de se adaptar a essa nova realidade do mercado e manter o funcionamento da empresa, pois a pandemia impôs a busca por novos meios de se fazer negócios, forçando a presença digital da marca o quanto antes (Rezende et al., 2020).

É importante destacar que mesmo antes da pandemia, o e-commerce gerava um grande impacto no consumo brasileiro, não apenas pelas compras realizadas de maneira virtual, mas também, aquelas que se realizavam em ambiente físico, mas eram influenciadas pelo ambiente digital. Contudo, é inegável que a pandemia acelerou e fomentou o consumo de maneira remota, e isso impôs que as empresas se reorganizassem e se reinventassem para se adequar a essa nova realidade para manter suas atividades (Rocha, 2020).

De acordo com estudo divulgado no relatório do BCG (Boston Consulting Group) sobre o consumo digital em mercados emergentes, é bastante comum que consumidores pesquisem por produtos online, mas apenas realizem a compra presencialmente. $\mathrm{O}$ estudo mostrou que a parcela de compradores que são influenciados pelo $e$-commerce, mas que continuam preferindo comprar de maneira física, representa mais que o dobro daqueles que realmente compram de maneira virtual (Padua, 2020).

Mas a pandemia mudou o comportamento de consumo, fomentando as compras online de modo a evitar a visita a locais públicos, seguindo as recomendações definidas pelo governo brasileiro e pela Organização Mundial da Saúde (OMS). Diante disso, o e-commerce está se fortalecendo cada vez mais porque lojas estão fechando e as pessoas estão ficando mais tempo em casa e recorrem à internet para atender suas necessidades básicas de consumo.

É notório que a operação de uma loja física costuma ser diferente daquela realizada em uma loja virtual, contudo, é preciso atentar para o ponto em que ambas convergem: nas duas modalidades há pessoas envolvidas, tanto quem compra quanto quem vende. Mesmo que a demanda do negócio não diminua (ou até aumente) em virtude da Covid-19, o lojista ainda terá que se preocupar com a equipe (Cruvinel, 2020). Nesse sentido, além de repensar estratégias de marketing digital para fomentar o e-commerce, é necessário que as empresas se preocupem com a integridade de seus colaboradores nesse cenário de pandemia, pois tal fator é um influenciador para escolha dos consumidores da empresa em que vão efetuar suas compras.

Diante disso, escalas reduzidas e trabalho remoto são algumas alternativas que vêm se mostrando mais comuns no ambiente das empresas para preservar a saúde de seus colaboradores, sem que isso gere um grande prejuízo à produtividade. No caso do homeoffice, a tecnologia possui um papel fundamental, seja através de um sistema de gestão na nuvem ou de ferramentas de suporte online. Além disso, algumas medidas adicionais de segurança passaram a ser adotadas na produção e na expedição de pedidos, diante do risco de contaminação das embalagens dos produtos (Piccolotto, 2020).

Em virtude desse novo cenário imposto pela pandemia, pode-se perceber que algumas mudanças na rotina das empresas são temporárias, mas outras, de certo, serão definitivas, modificando os hábitos de consumo e criando novas tendências de marketing digital. $\mathrm{O}$ isolamento social fez com que o consumidor tivesse que ficar mais tempo em casa e, consequentemente, passasse a navegar ainda mais na internet, seja a trabalho, estudo, lazer ou para adquirir algum tipo de produto ou serviço. A necessidade de ficar em casa obrigou as pessoas a comprarem produtos ou serviços de forma remota, como também a buscarem novas alternativas de entretenimento e conhecimento (Rezende et al., 2020).

As buscas na internet, diante disso, aumentaram substancialmente e cada vez mais pessoas estão buscando no âmbito virtual algum tipo de produto ou serviço. A atual crise que o mundo enfrenta vem, assim, obrigando as pessoas a repensarem suas atitudes e gastos, além de refletirem cada vez mais em como será o futuro. O isolamento social vem gerando grandes impactos em todas as áreas da economia e promovendo mudanças de hábitos, principalmente na forma de consumo de 
produtos e serviços. Aquelas empresas que vêm conseguindo se adaptar às novas demandas do mercado e dos consumidores vêm obtendo êxito em suas negociações e conseguindo se manterem ativas.

Contudo, nem todos os setores estão conseguindo manter o fluxo, e, com isso, necessitam traçar alternativas eficazes para conter a crise. O varejo está assistindo à redução das compras por impulso, seja pela quarentena ou pela insegurança econômica. Há, ainda, a diminuição dos gastos com coisas supérfluas e a priorização daquelas que são de primeira necessidade. Diante disso, as compras impulsivas tiveram uma grande queda, obrigando empresas a repensarem estratégias para chegar até o consumidor (Rocha, 2020).

Portanto, buscando se alinharem as novas expectativas do mercado, as empresas começaram a reposicionar sua forma de realizar comunicação com os clientes. Assim, no futuro do mercado empresarial, são estimadas mudanças em decorrência das tendências de marketing digital desencadeadas pela pandemia de Covid-19.

\subsection{Fomento do e-commerce no cenário atual e a demanda pelo marketing inteligente}

É fato que a pandemia do coronavírus desencadeou grandes desafios para empresas se manterem no mercado e, nesta ótica, os negócios online passaram a ter importância fundamental na relação entre empresas e clientes. Algumas empresas, como as grandes varejistas e segmentos de produtos e serviços essências não sofreram grandes impactos com as restrições sanitárias impostas, porém os serviços não essenciais e as pequenas e médias empresas tiveram que rapidamente desenvolver estratégias para se manterem ativas e não falirem nessa pandemia.

Tal cenário impôs a todos estes atores o desenvolvimento de estratégias mais eficientes para manter em funcionamento as engrenagens da economia. Ou seja, tornou-se necessário inovar, desenvolver e ampliar canais que permitam realizar vendas de maneira eficiente, cômoda e segura para os consumidores e para que o fluxo financeiro seja mantido, garantindo-se, assim, a existência das empresas no período pós-pandemia (Rezende et al., 2020).

Ainda conforme os referidos autores, o impacto gerado pelo coronavírus sobre todo o mundo e, em particular sobre o Brasil, obrigou as empresas de todos os tamanhos, assim como, negócios de todas as variedades, a se ajustarem de maneira muito rápida à nova realidade imposta pela pandemia. Diante disso, inovar tornou-se a palavra da vez nesse novo cenário de crise.

Como mencionado anteriormente, é evidente que a pandemia impulsionou o mercado de e-commerce no mundo e também no Brasil, no entanto, o que faz essas mudanças serem estruturais e não apenas momentâneas? Em resposta a esse questionamento, podem ser pontuados dois vetores de mudanças estruturais que devem acelerar a manutenção do e-commerce no varejo brasileiro: aumento no acesso à Internet e mudança de hábitos de consumo (Padua, 2020).

$\mathrm{O}$ acesso à internet e a cada vez maior aquisição de produtos e serviços no ambiente virtual são comportamentos do consumidor que seguramente se incorporaram à sua rotina, uns mais outros menos, mas todos necessitando recorrer ao $e$ commerce para algum tipo de necessidade nessa pandemia. Tais hábitos revelaram que a não essencialidade de se dirigir a lojas físicas para efetuar compras, e essa comodidade passou a ser incorporada à rotina de muitos brasileiros, com grande possibilidade de permanecer em seus hábitos.

Em vista disso, as empresas precisam manter as estratégias de marketing digital e de fomento ao e-commerce para que haja a fidelização de seus consumidores, além de ser necessário um marketing positivo voltado à preocupação da organização com a sustentabilidade, tão falada e necessitada nesse período de pandemia. Facilidade nas compras online, divulgação em redes sociais, rapidez na entrega dos produtos, canais ágeis de comunicação e valorização dos clientes e colaboradores são algumas estratégias que se mostram eficazes para tornar a empresa bem avaliada pelos consumidores e, assim, continuar a manter suas atividades de maneira satisfatória mesmo no período pós-pandemia.

Essas novas estratégias para as vendas de produtos, com o objetivo de manter minimamente a comercialização de 
bens para a geração de receita nas empresas são bastante necessárias. Se forem bem-sucedidas, essas estratégias tendem a mitigar os efeitos econômicos e financeiros decorrentes da interrupção das atividades produtivas e dar algum fôlego às empresas, visto que o futuro ainda está repleto de incertezas (Ferreira Júnior \& Santa Rita, 2020).

Nessa perspectiva, as vantagens de uso do comércio eletrônico trazem benefícios tanto para os consumidores quanto para os vendedores. O principal benefício para os consumidores é a compra eficiente, visto que as lojas online proporcionam uma grande variedade de produtos, preços mais baixos e um serviço mais personalizado, procurando sempre inovar em seus serviços e produtos (Martins, 2020).

Já o diferencial para as empresas é que o e-commerce proporciona um baixo custo em relação ao capital e ao trabalho em comparação ao varejo tradicional, pois consegue suprir as demandas com uma menor estrutura, sem que haja a necessidade de investimentos em ativos físicos, como em lojas, estacionamentos, decorações e outros. Pelo fato de não utilizarem lojas, as empresas que se valem do comércio virtual como uma ferramenta de venda conseguem operar com uma quantidade menor de funcionários, tendo um gasto menor com despesas salariais, treinamentos e comissões (Martins, 2020).

Desse modo, o e-commerce possibilita que as empresas tenham vantagens em relação ao custo, gerando um melhor relacionamento com o cliente em virtude de o preço ser menor quando comparado às lojas físicas. Outra vantagem é a flexibilização e agilidade que se alcança com o uso dessa plataforma, pois o consumidor pode fazer as compras no conforto de sua casa e, por ser online, pode ser feita a qualquer hora do dia, todos os dias da semana, enquanto a loja física funciona apenas em horário comercial (Rocha, 2020).

Se antes da pandemia de Covid-19 muitas pessoas possuíam medo de efetuarem compras online, agora grande parte delas se viram obrigadas a superarem esse medo devido à impossibilidade de realização de compras em lojas físicas. Uma vez que o consumidor experimenta a compra online, ele aumenta sua confiança no serviço e, além disso, identifica a comodidade, que é um dos principais estimuladores do e-commerce em países desenvolvidos, segundo o BCG. Esses fatores possivelmente farão com que o indivíduo mantenha ou até mesmo amplie o hábito de comprar online no período pós-pandemia (Padua, 2020).

É importante destacar, no entanto, que a alta demanda pelas compras online pode gerar dificuldades na empresa em atender a todos os pedidos. Em vista disso, é necessária a adoção de estratégias para otimizar a produção e a venda, de maneira a tornar o atendimento célere e satisfatório, pois a rapidez na celebração do negócio e a entrega do produto ou serviço final é um fator de valoração da empresa e, de certo, um marketing eficiente e inteligente.

Em relação ao marketing, é bem provável que a tentação de redução do valor investido possa ser a estratégia adotada por algumas empresas, pois seria uma maneira rápida de reduzir os custos nesse cenário de recessão econômica. No entanto, não ser visto nesse momento em que todos os produtos e serviços estão mais disponíveis no ambiente virtual pode significar não ser lembrado mais adiante. Desse modo, com o bom senso que o atual contexto exige é fundamental o uso inteligente das redes sociais e de outros canais para manter a presença digital da empresa. A criação de conteúdos interessantes que ajudem a informar, entreter e solidificar a relação da empresa com o público se mostra fundamental (Ferreira Júnior, 2020).

Uma boa experiência para o cliente deve ser sempre um objetivo do e-commerce e, desse modo, a prestação de um atendimento de qualidade e a oferta de soluções eficazes e necessárias ajudam a causar uma boa impressão nos consumidores, notadamente no atual cenário em que muitos clientes buscam o comércio virtual pela primeira vez (Gouvêa, 2020).

As empresas que conseguirem desenvolver uma maior interação com o seu público estarão em vantagem, mas os negócios que não se adaptarem ao meio online estarão fadados a reduzir drasticamente suas vendas e até mesmo a fecharem suas portas, pois a pandemia solidificou o e-commerce e aqueles consumidores que antes se mostravam reticentes em utilizar o meio online para compras agora estão sendo obrigados a fazê-lo, e essa é uma realidade que muito provavelmente será mantida no período pós-pandemia (Rocha, 2020).

Contudo, há que se ressaltar que apesar do e-commerce ter apresentado um aumento significativo por conta da 
pandemia, um ponto que foi impactado de maneira negativa foram os prazos de entrega, que ficaram maiores. A pesquisa da Ebit-Nielsen (2020) revelou que no primeiro semestre de 2020, a média de prazo de entrega de compras online foi de 11,3 dias contra 10,6 dias nos mesmos meses do ano de 2019. Já a taxa de pedidos entregues no prazo foi $14 \%$ neste ano, $2 \%$ maior do que no ano passado.

Todavia, mesmo com esse aumento nos prazos de entrega, é possível observar que o e-commerce foi fomentado de maneira significativa na pandemia e as compras online são uma realidade bem mais presente no comportamento consumidores brasileiros. Diante disso, Garcia, Silva, Katchorovski e Volanin (2020) alertam que "[...] a segurança do e-commerce deve ser levada a sério pelos gestores, pois além de dar segurança de compra ao cliente, ela faz com que a organização evite prejuízos”.

As empresas que não desenvolverem uma estrutura para se adequarem a essa nova realidade, buscando ferramentas para garantir a segurança e agilidade nas compras, bem como estratégias criativas para atrair a atenção dos consumidores, possivelmente não atenderão às novas expectativas do mercado, ficando para trás na corrida pela fidelização da clientela.

\section{Conclusão}

A partir do presente estudo, foi possível observar que o e-commerce já vinha apresentando uma expansão no Brasil mesmo antes da pandemia do coronavírus, mas, devido ao isolamento social, as compras online passaram a ser utilizadas em grande proporção. As empresas que entenderam e se adaptaram a essa nova realidade possuem maiores chances de superar a pandemia, mantendo-se ativas e com a possibilidade de até ampliar seus negócios. Em que pese o fato da pandemia ter gerado efeitos nefastos tanto na saúde da população, quanto no mercado empresarial, ela pode ser vista como uma oportunidade para criação da presença digital das empresas e para conquistar consumidores de todo o Brasil.

Provavelmente o mundo não voltará a ser como era antes, pois os novos hábitos de consumo vieram para dar nova configuração ao mercado. É fato que o pensamento do consumidor se transformou, e o planejamento das empresas deve seguir essa nova realidade. A necessidade de ficar em casa está levando os consumidores a desenvolverem uma nova visão sobre suas prioridades em relação a despesas com itens não essenciais e na forma como adquirem seus produtos.

Buscar novas tendências de marketing digital, ditadas por esses novos comportamentos, se faz essencial para que as empresas mantenham sua produtividade ativa. A preocupação das empresas deve ser em atender de maneira célere e satisfatória às necessidades dos consumidores, cada vez mais presentes no ambiente virtual e atentos aos preços, promoções e à conveniência na compra. Uma boa experiência de compra online será um diferencial e a relação entre custo e benefício será cada vez mais priorizada pelos clientes. Além disso, a comunicação eficaz e ampla com os consumidores e a preocupação das empresas com a sustentabilidade são atributos cada vez mais observados pelos consumidores na opção pela comora em alguma empresa.

Em tempos onde o isolamento social é essencial, o e-commerce vem ampliando sua importância e certamente deverá se manter em ascensão no período pós-pandemia. Desse modo, é fundamental que as empresas construam e desenvolvam estratégias adequadas para o fomento às compras remotas, de maneira a aproveitar todas as oportunidades que estão emergindo no atual cenário brasileiro.

Também é de fundamental importância que as empresas prezem pela eficácia de seus canais digitais de contato com os clientes, diante do maior volume de consumidores iniciantes no âmbito virtual, visto que, estes apresentam mais dúvidas e dificuldades no processo de compra. Reforçar o relacionamento com o consumidor, tirando suas dúvidas e fornecendo um atendimento personalizado são fatores que agregam valor à empresa e se constituem como diferencial para fidelização dos clientes.

Constata-se, desse modo, que a pandemia acelerou o futuro de implementação maciça do comércio digital, gerando um crescimento acima da média de novos usuários do e-commerce no Brasil e impondo aos empresários a necessidade de se 
reinventarem, elaborarem estratégias de marketing digital e adaptarem seus negócios ao novo contexto de consumo. A estratégia vem se mantendo vantajosa, existindo grande tendência de que sejam mantidas estas técnicas de vendas no período pós-pandemia.

Cabe salientar que a pesquisa teve algumas limitações em virtude de a pandemia não ter acabado, e a quantidade de estudos acadêmicos sobre a temática ainda é escassa, bem como os impactos que ela vem gerando só poderão ser efetivamente mensurados quando finalmente o mundo conseguir superá-la. Contudo, o presente estudo, ao reunir dados de outras publicações sobre a temática, pode contribuir sobremaneira para estudos futuros.

Com a pandemia, tanto as vendas, quanto a comunicação com o público no âmbito online passaram a ser uma nova realidade para muitas empresas, um cenário que antes parecia distante da realidade. A manutenção deste vínculo pode ser uma chave para abrir as portas do futuro pós-pandemia, tanto para as grandes empresas, quanto para permitir aos pequenos empresários o acesso a novos mercados e novos clientes.

Como sugestões de pesquisas futuras é possível fazer um estudo sobre os impactos da pandemia nas teorias do marketing digital e do reposicionamento empresarial nas tecnologias de suporte do e-commerce. Bem como é possível fazer um estudo dos impactos nos setores de marketing digital e e-commerce comparando o uso dessas ferramentas em um mundo antes, durante e pós-pandêmico

\section{Referências}

Almeida, M. R. C., Froemming, L. M. S., \& Ceretta, S. B. N. (2020). Comportamento de consumo em meio a pandemia da covid-19. In: XXV Jornada de Pesquisa em Administração e Marketing, 6(6), Salão do Conhecimento UNIJUÍ.

Batista, K., Saran, A. P. M., Limongi, R., Silva, A. L. B., \& Gomes, A. C. (2020). Organizational communication in social media in times of COVID-19. Revista Eletrônica Gestão \& Sociedade, 14(39), 3689-3697, Especial COVID-19.

Cruvinel, I. B. (2020). Marketing digital em tempos de pandemia. In: Gestão \& Tecnologia. Faculdade Delta Ano IX, 1. http://faculdadedelta.edu.br/revistas3/index.php/gt/article/view/57

Creswell, J. W. W (2010). Projeto de pesquisa: métodos qualitativo, quantitativo e misto. (2a ed.), Bookman.

Ferreira, L. (2020). Como será o mundo pós-pandemia? In: UNESC-AICOM. https://www.unesc.net/portal/aicom/blog/47946-como-sera-o-mundo-pospandemia-professores-da-unesc-apontam-desafios-e-solucoes

Fiocruz. (2020). O que é o novo coronavírus? https://portal.fiocruz.br/pergunta/o-que-e-o-novo-coronavirus

Garcia, L. A., Silva, J. E. P., Katchorovski, Y.F., \& Volanin, F. (2020). Análise do E-Commerce Como Oportunidade Promissora Para a Cidade de Guarapuava-PR e Região. In: X Congresso Brasileiro de Engenharia da Produção. Paraná, APREPRO.

Gouvêa, K. (2020). A economia e a sustentabilidade pós-pandemia da Covid-19. In: Portal Comunique-se. https://portal.comunique-se.com.br/a-economia-ea-sustentabilidade-pos-pandemia-da-covid-19-237768/

Guimarães Júnior, D. S., Nacimento, A. M., Rodrigues, G. P. A., \& Santos, L. O. C. (2020). Efeitos da Pandemia do COVID-19 na Transformação Digital de Pequenos Negócios. Revista de Engenharia e Pesquisa Aplicada, 5(4), 1-10.

Lara, J., Afonso, T., Elias, R. K., Afonso, B. P. D., \& Tissot-Lara, Thalles A. (2020). Marketing e logística: em busca da satisfação e lealdade do consumidor de compras on-line. Revista Horizontes Interdisciplinares da Gestão, 4(2).

Lemos, V. (2020). Coronavírus: os indícios que apontam que o Sars-Cov-2 circulava no Brasil antes do primeiro diagnóstico oficial. In: BBC Brasil. https://www.bbc.com/portuguese/brasil-52742802

Maciel, D. (2020). Sustentabilidade ganha importância com pandemia do novo coronavírus. 2020. https://diariodocomercio.com.br/negocios/sustentabilidadeganha-importancia-com-pandemia-do-novo-coronavirus/

Martins, R. (2020). Crescimento do e-commerce em meio à pandemia do coronavírus. In: Lifeapps. https://lifeapps.com.br/crescimento-do-e-commerce-emmeio-a-pandemia-do-coronavirus/

Melo, F. (2017). Direito ambiental. (2a ed.), Forense.

Padua, F. (2020). Os impactos do coronavírus no e-commerce brasileiro. In: Ligafeausp. https://www.ligafeausp.com/single-post/2020/07/22/Os-impactos-docoronav\%C3\%ADrus-no-e-commerce-brasileiro

EBIT-NIELSEN. (2021). E-Commerce no Brasil cresce $47 \%$ no primeiro semestre, maior alta em 20 anos. Static.poder360. https://static.poder360.com.br/2020/08/EBIT-ecommerce-Brasil-1semestre2020.pdf 
Research, Society and Development, v. 10, n. 5, e45210515054, 2021

(CC BY 4.0) | ISSN 2525-3409 | DOI: http://dx.doi.org/10.33448/rsd-v10i5.15054

Piccolotto, L. (2020). Mundo pós-pandemia vai ser mais digital e, ao mesmo tempo, mais humano. In: JOTA, jun. 2020. https://www.jota.info/coberturasespeciais/inova-e-acao/mundo-pos-pandemia-vai-ser-mais-digital-e-ao-mesmo-tempo-mais-humano-09062020

Rezende, A. A., Marcelino, J. A., \& Miyaji, M. (2020). A reinvenção das vendas: as estratégias das empresas brasileiras para gerar receitas na pandemia de covid-19. In: Boletim de Conjuntura (BOCA), 2(6), 53-69.

Rocha, R (2020). Mudanças nas tendências de marketing digital com a Covid-19. In: E-commercebrasil. https://www.ecommercebrasil.com.br/artigos/m udancas-nas-tendencias-de-marketing-digital-com-a-covid-19/

Severino, A. J. (2007). Metodologia do trabalho científico. (23a ed.), Cortez. 